\title{
REPRESENTASI PESANTREN DAN KESALAHAN BERBAHASA DALAM NOVEL "CIUMAN TERAKHIR AYAH" KARYA: MAUFIQURRAHMAN SURAHMAN
}

\author{
Kadarisman \\ Universitas Wiraraja \\ Email: kedarisman84@gmail.com
}

\begin{abstract}
Abstrak
Novel merupakan salah satu jenis karya sastra berbentuk prosa yang di dalamnya terdapat unsur-unsur pembangun seperti alur, tokoh, latar, dan tentu saja bahasa. Sebagai bagian dari karya sastra, novel juga memiliki genre tersendiri. Karya sastra Indonesia terus ber-evolusi sesuai dengan tuntutan dan perkembangan zaman, serta sesuai dengan situasi dan kondisi pada masyarakat penulis dan pembacanya.

Pada novel Ciuman Terakhir Ayah karya Maufiqurrahman Surahman akan dijumpai potret dunia pesantren yang sangat kental. Hal ini menandakan bahwa sosiologi pengarang sangat berpengaruh dalam mengonstruksi sebuah karya sastra. Hal tersebut tampak pada cara pengarang memilih diksi, alur, membangun watak tokoh, dan menciptakan suasana tertentu pada novel tersebut.

Di sisi lain, masih ditemukan beberapa kesalahan berbahasa pada novel Ciuman Terakhir Ayah. Oleh karena itu pemahaman terhadap kaidah kebahasaan sangat penting, karena karya sastra menggunakan bahasa sebagai media penghubung antara pengarang dan pembacanya.
\end{abstract}

Kata Kunci: Representasi, Pesantren, Kesalahan Berbahasa

\begin{abstract}
The novel is one type of prose literary work in which there are building elements such as plot, character, setting, and of course language. As part of literature, novels also have their own genre. Indonesian literature continues to evolve in accordance with the demands and development of the times, and in accordance with the situation and conditions in the community of writers and readers.

In the novel Ciuman Terakhir, the work of Maufiqurrahman Surahman will be found in a portrait of the world of pesantren which is very thick. This indicates that the sociology of the author is very influential in constructing a literary work. This can be seen in the way the author chooses diction, plot, builds character, and creates a certain atmosphere in the novel.

On the other hand, there are still some language errors in the novel The Last Kiss of the Father. Therefore understanding of linguistic rules is very important, because literary works use language as a medium of liaison between authors and readers.
\end{abstract}

Keywords: Representation, Islamic Boarding School, Language Mistakes

\section{Pendahuluan}

Pertengahan Tahun 1998, dunia kesusastraan Indonesia "digemparkan" dengan dinobatkannya Ayu Utami sebagai pemenang dalam sayembara penulisan novel yang diselenggarakan oleh DKJ (Dewan Kesenian Jakarta). Bukan karena Ayu Utami menjadi penulis perempuan pertama yang berhasil meraih penghargaan tersebut, melainkan novelnya yang berjudul "Saman" yang kemudian menjadi cikal- bakal lahirnya karya sastra serupa: feminis, erotis, dan tentu saja vulgar. Melalui novel tersebut, seolah-olah Ayu Utami menjadi keran pembuka keliaran imajinasi bagi penulis-penulis perempuan lain yang tidak kalah menantang, seperti Djenar Maesa Ayu, Dewi Lestari, Fira Basuki, Naning Pranoto, dan lain-lain.

Terlepas dari segala kontroversi yang mengikutinya, Ayu Utami beserta penulis lain yang mengusung tema perempuan, 


\section{Kadarisman}

tubuh, dan seks telah menjelma sebagai genre baru dalam dunia kesusastraan Indonesia (genre sastra wangi, sastra pantat, sastra perempuan, dan sebutan lainnya). Eksistensi mereka di dunia kesusastraan selalu menjadi topik ulasan kritikus di koran-koran dan majalah mingguan yang memuat kolom sastra. Bentuk ulasannya pun beragam. Ada yang menentang keberadaan mereka, tapi tidak sedikit pula yang terang-terangan memberikan dukungan. Sejak saat itu, kesusastraan Indonesia seolah-olah kembali menemukan "gairah" setelah sebelumnya sempat lelap karena terkungkung oleh rezim orde baru.

Dua tahun berselang, ketika orang-orang masih belum tuntas membicarakan genre sastra di atas, kesusastraan Indonesia kembali dikejutkan dengan kehadiran wacana sastra pesantren. Entah kebetulan atau tidak, Tahun 2000 merupakan waktu di mana Indonesia mengalami masa transisi kepemimpinan dengan berhasilnya Gus Dur terpilih sebagai Presiden Indonesia keempat pada Tanggal 22 Oktober 1999 menggantikan BJ. Habibie. Gus Dur yang notabene tumbuh dan besar di lingkungan pesantren dianggap memiliki peran besar dalam melahirkan genre sastra tersebut. Menurut M. Faizi (2003), Gus Durlah yang membukakan pintu gerbang kepesantrenan: pintu tempat orang-orang luar masuk dan melihat-lihat pesantren, dan dia pulalah yang mengajak civitas pesantren untuk keluar dan menunjukkan diri kepada dunia.

Di lain pihak, ada yang berasumsi bahwa sastra pesantren lahir sebagai bentuk counter attack terhadap genre sastra yang sebelumnya (sastra wangi, sastra pantat, sastra perempuan). Sastra pesantren dianggap memiliki kemampuan untuk mengimbangi keliaran sastra wangi yang lebih memublikasikan tubuh, seks, dan kebebasan. Sementara sastra pesantren lebih memosisikan sebagai penawar dari keliaran itu, cenderung arif, religius, dan bermoral.

Meski kedua genre sastra tersebut sama sekali bertolak belakang, akan tetapi ada benang merah yang menjembatani keduanya, yakni "kontroversi". Baik sastra wangi dan sastra pesantren, keduanya sama-sama tidak pernah selesai diperdebatkan bahkan sampai sekarang ini. Untuk sastra wangi, dianggap bukan merupakan genre sastra dikarenakan hanya menyesuaikan dengan kebutuhan pasar (provit oriented).

Sementara untuk sastra pesantren tidak kalah banyak yang menentang kehadirannya, bahkan termasuk dari kalangan pesantren sendiri misalnya, Binhad Nurrohmat. la berpendapat bahwa, definisi sastra pesantren itu tetap rancu dan problematik. Sebab, apa yang dimaksud dengan karya/ genre sastra pesantren selama ini tidak jauh berbeda dengan karya sastra lain pada umumnya kecuali hanya pada persoalan tema. Padahal, tema bukanlah ukuran pembentuk genre sastra. Menurutnya, "Identifikasi pada apa yang disebut sebagai sastra pesantren sebatas berurusan dengan aktualisasi tema atau latar belakang pengarangnya yang berhubungan dengan keislaman, kesantrian, dan kepesantrenan; dan bukan berdasarkan unsur-unsur atau kecenderungan "bentuk" kesusastraan yang khas dimiliki oleh sastra pesantren itu" (Nurrohmat, 2007).

Tentu Binhad sangat beralasan. Pasalnya, sebelum sastra pesantren naik daun pada tahun 2000-an, telah lahir penulis-penulis dengan corak, tema, dan latar belakang pesantren. Sebut saja Hamka, Ahmad Tohari, M. H. Ainun Nadjib, Acep Zam-zam Noer, Jamal D. Rahman, dan lain-lain. Penulis-penulis tersebut juga memiliki latar belakang pesantren, menulis karya sastra dengan corak pesantren, dan 
tak jarang pula mengusung tema-tema pesantren.

Tahun 2003, kesusastraan Indonesia kembali bergejolak dengan hadirnya gelombang besar bacaan pop yang merambah dunia remaja yang dimotori oleh Dyan dengan novelnya "Dealova". Seolah tidak mau tinggal diam, dunia pesantren kembali meresponnya melalui novel "Santri Semelekete” karya Ma'rifatun Baroroh. Novel ini juga menyinggung persoalan remaja, berbau pop, akan tetapi tetap tidak meninggalkan nilai-nilai kepesantrenan. Pada perkembangan selanjutnya, banyak pula lahir karya-karya seperti novel ini, yang juga menjadi cikal-bakal lahirnya genre baru "sastra pop pesantren".

Selain dari unsur penulis, meledaknya istilah sastra pesantren tak bisa lepas juga dari banyaknya kritikus sastra Indonesia yang mengulas karya-karya sastra bernuansa religius itu. Damono (Yudiono: 2009) pada pengantarnya menjelaskan bahwa "dalam perkembangan sastra modern di manapun kritik sastra semakin lama semakin penting kedudukannya dalam perbincangan tentang kesusastraan." Sekali lagi, terlepas dari segala kontroversi yang mengikutinya, sastra pesantren tetaplah sebuah keniscayaan yang mewarnai khazanah kesusastraan Indonesia.

\section{Ciuman Terakhir Ayah: Sebuah Montase Dari Pesantren}

Membaca novel ini, pembaca seolaolah dihadapkan pada sebuah lukisan. Dunia pesantren dengan segala dinamikanya digambarkan secara gamblang kepada pembaca. Melalui novel ini, pembaca dapat dengan mudah memahami bagaimana suasana, pendidikan, kehidupan, dan juga sistem yang berlaku di dunia pesantren. Misalnya pada kutipan berikut:
Semua dijelaskannya satu persatu hingga aku mengerti dan mengenal nama-nama gedung-gedung pesantren yang notabene menggunakan nama kota di timur tengah dan tokoh, sepertigedung Mekkah, gedung Hafsah, gedung Ruqoyyah, gedung Khotijah, dan seterusnya. Berikut namanama kantor yang juga tertulis dengan bahasa arab seperti Maktabul Munadzomah Littholibaat (Kantor Organisasi Santriwati), Maktabul Markazi-iUghah Littholibaat (Kantor Markas Bahasa Untuk Santriwati), Maktabul Idzaroh (Kantor Administrasi, dan seterusnya), (Surahman, 2013: 60).

Sekilas, kutipan tersebut tampak sederhana dan tidak terlalu fundamental. Akan tetapi penulis membuat tampak sebagai sebuah lukisan luar biasa ketika dipadukan dengan gambaran-gambaran lain yang juga sederhana. Pengaran bukan hanya menuangkan lukisan bangunanbangunan pesantren pada sebuah kanvas, tetapi juga memberikan gambaran tentang sistem, corak, serta potret kehidupan dunia pesantren.

Membaca novel Ciuman Terakhir Ayah seperti dihadapkan pada biasbias strukturalisme. Sebagaimana dijelaskan Ratna (2009) bahwa "struktur lebih dari sekadar unsur-unsur dan totalitasnya, karya sastra lebih dari sekadar bahasa sebagai medium, karya sastra lebih dari sekadar penjumlahan bentuk dan isinya. Unsurunsur memiliki fungsi yang berbedabeda, dominasinya tergantung pada jenis, konvensi, dan tradisi sastra." Pada makna ini, pengarang dengan 
Kadarisman

total menyatukan setiap unsur dunia pesantren ke dalam kesatuaan yang utuh.

Sesuai dengan proposisi Durkheim (Ratna, 2009) "mengenai masyarakat, maka dalam karya, totalitas selalu lebih besar dan lebih berarti dari jumlah unsurnya. Kualitas karya dinilai dalam totalitasnya, bukan akumulasi unsurnya." Sementara pada novel Ciuman Terakhir Ayah, penulis juga menyertakan detaildetail kecil tentang dunia kepesantrenan, termasuk urusan mandi. Misalnya pada kutipan berikut:

Pagi itu, tanpa banyak protes, para akhwat sudah berdiri berbaris panjang di kamar mandi qitor, konon disebut qitor karena bentuk kamar mandinya yang panjang lurus, layaknya kereta api. Akhwat pun jika mandi khususnya pagi hari, mereka mengantri seperti antrian para penumpang kereta api yang tengah menunggu giliran mendapat tiket. Tak ada yang aneh di Pesantren. Semua terjadi begitu alamiah dan sistematis, akhwat seolah sudah terbiasa berlama-lama mengantri tanpa ada satu pun yang teriak-teriak dan membuat gaduh. Dengan sabar para akhwat itu menunggu giliran (Surahman, 2013: 163).

Kutipan di atas merepresentasikan bagaimana suasana pesantren di pagi hari. Penulis menyuguhkannya dengan kesederhanaan bahasa, sehingga tampak tergambar jelas pula spirit pesantren yang naturalis, apa adanya, dan dalam. Hal ini menjadi kekuatan tersendiri bagi teknik kepenulisan Maufiqurrahman.
Lantas bagaimana dengan moral? Seperti pernah disinggung sebelumnya, bahwa moral biasanya tetap mejadi bagian tak terpisahkan pembangun struktur karya sastra yang ditulis oleh sastrawan berlatar belakang pesantren. Dari novel ini, pembaca diajak untuk benar-benar menjadi pribadi yang sabar dalam menghadapi segala cobaan, sederhana dalam menjalani kehidupan, serta tangguh dalam menyelesaikan setiap persoalan. Meski nyaris tidak kita temui tokoh antagonis dalam novel ini, ternyata tokoh Nina sudah cukup mampu mengemban keselarasan alur cerita dan permainan konflik dari awal sampai akhir.

Penulis cukup piawai memainkan kesederhanaan bahasa melalui kesederhanaan tokoh Nina. Misalnya pada kutipan berikut:

Pagi itu, aku hanya bisa menangis tak tahan menahan rasa sakit. Ah, anak seumurku sudah berpikir efek sosial pada seorang wanita cacat, pertanyaan-pertanyaan negatif dalam benakku mulai berbisik di telinga membuat buram warna hidupku. Sepertinya, harapan ini. Aku memang sempat putus asa menghadapi ujian berat ini, namun aku masih berpikir positif dan berharap Tuhan menyimpan maksud yang terbaik (Surahman, 2013: 43).

Sebagai karya sastra, novel ini sangat banyak mengandung pesan moral. Pembaca bisa belajar banyak tentang nilai-nilai budi pekerti, pembangunan karakter, serta perilakuperilaku positif yanag lain. Ini menjelaskan kepada pembaca bahwa 
ISSN 2548-9119

karya sastra selain memiliki fungsi rekreatif, juga memiliki fungsi edukatif.

Sampai di sini telah sedikit terbaca, bahwa sastra pesantren tidak serta merta menyampaikan pesan keagamaan secara formalistik bahkan pengistilahan-pengistilahan keagamaan dalam diksi-diksinya belaka. Sebagaimana dijelaskan Adnan (2012) bahwa "pada saat merujuk substansi tujuan disuguhkannya sebuah karya sastra, sastra pesantren mencoba menempuhnya melalui pesan moral yang kuat, nalar kritis yang luar biasa, serta pembacaan terhadap pesan keadilan yang terus berkembang sesuai dengan kebutuhan. Dan ini bisa dikatakan sebuah hasil penyarian di mana agama akan tetap sesuai dan dibutuhkan sebagai pedoman manusia untuk selama-selamanya."

Lebih Ianjut Adnan (20012) menjelaskan, "nilai religiusitas dalam sastra pesantren dapat diukur pula sebagai ruh yang terus menyesuaikan diri dengan kebutuhan jiwa dan psikologi yang dialami pembacanya." Maka tidak aneh, apabila sebuah karya sastra yang mengusung dan dilatarbelakangi tradisi pesantren dapat dinikmati secara universal, sekalipun oleh kalangan pembaca non-muslim misalnya. Inilah aset yang sebenarnya menjadi beban tanggung jawab dalam dunia sastra kepesantrenan, harus mampu memunculkan kekuatan universalitas dalam produk sastranya. Ukhty, sini makan bareng," kata Ukhty Ira setibanya kami di kamar, ia lagi makan juga. Rupanya ia baru saja mendapat kiriman paket makanan dari rumahnya. Aneka khas makanan Padang tersaji di atas tikar yang tergelar di atas lantai, kami pun mendekat memenuhi tawaran makan bersama Ukhty Ira. Sambil menikmati makanan Padang itu, hatiku kembali berdesir, "Subhanllah, baru saja aku bersyukur atas nikmat-Mu, ya Rob. Kini Kau tambah lagi nikmat-Mu yang lebih banyak. Terima kasih, ya Rob... (Surahman, 2013: 88).

Hal ini kembali menegaskan kepada pembaca tentang bagaimana harus mensyukuri setiap nikmat yang diberikan Tuhan yang Maha Esa. Dengan kata lain, kita tidak harus belajar agama atau pun sekolah untuk mempelajari nilai-nilai karakter dan budi pekerti. Karya sastra pun ternyata cukup memberikan ruang yang cukup luas untuk menyampaikan itu semua.

Faktor lain yang membuat karya ini tampak menarik adalah dari pemilihan diksi. Novel ini tidak terlalu menitikberatkan pada kerumitan bahasa yang mengharuskan pembaca mengernyitkan dahi untuk memahami alur ceritanya. Sebaliknya, novel ini lebih banyak menggunakan bahasa keseharian yang membuatnya lebih dekat dengan kehidupan masyarakat, terutama dunia remaja. Di dalamnya banyak kita jumpai kata "Kepingin (ingin), emang (memang), nggak (tidak), ngeliatin (melihat), kayak (seperti), nemaniku (menemaniku)" dan sebagainya.

Pemilihan diksi-diksi tersebut menjadikan novel "Ciuman Terakhir Ayah" karya Maufiqurrahman Surahman menjadi lebih ringan, mudah dipahami, dan lebih dekat dengan pembaca. Penulis seolah-olah hendak menyampaikan bahwa menulis karya sastra itu tidak harus dibuat rumit. Kita 
Kadarisman

bisa menciptakannya meski dengan penuh kesederhanaan.

2. Semacam Gagasan yang Tergesa Disampaikan

Bahasa merupakan unsur penting dalam karya sastra. Sesuai dengan salah satu fungsinya (bahasa sebagai media ekspresi diri), bahasa digunakan sastrawan sebagai media untuk menyampaikan ide atau gagasannya kepada masyarakat luas. Dalam dunia sastra, bahasa dapat berfungsi sebagai "jembatan" yang menghubungkan antara sastrawan dengan pembacanya. Oleh karena itu, menurut Ashcroft dkk. (Soewandi dan Mokamat, 2003), "bahasa tidak hadir sebelum ataupun sesudah fakta, melainkan ada di dalam fakta itu sendiri. Bahasa membentuk realitas dengan satu cara yang jelas; ia menyediakan istilah-istilah tertentu, dan bukan yang lainnya, untuk kita bicarakan tentang realitas."

Menggunakan bahasa dengan benar (baik secara struktur maupun penulisan) dalam karya sastra sangatlah penting. $\mathrm{Hal}$ itu dimaksukan untuk menjaga kualitas dan menghindari ambiguitas tafsir para pembaca. Memang, karya sastra merupakan bentuk karangan fiksi. Tidak seperti karya ilmiah atau laporan penelitian yang menekankan pada penggunaan bahasa baku, karya sastra lebih fleksibel dalam tata aturan kebahasaannya. Akan tetapi dalam karya sastra, penulis juga memiliki kewajiban untuk menjaga logika teks sehingga pembaca tidak rancu dalam memahami makna kata yang dibacanya.

Akan tetapi, tidak dapat dipungkiri bahawa terkadang di balik kesempurnaan setiap karya sastra, adakalanya terdapat celah yang membuat nilai karya tersebut "sedikit" berkurang. Celah tersebut dapat berupa ketidaktelitian penulis atau pun penyunting dalam menyusun struktur bahasa karya itu sendiri.

Dalam novel "Ciuman Terakhir Ayah" karya Maufiqurrahman Surahman terkadang dijumpai kesalahankesalahan tersebut, baik yang berupa kesalahan ketik, kesalahan penggunaan tanda baca, juga penyusunan struktur kalimat. Adapun kesalahan-kesalahan tersebut tampak pada tabel berikut: 
TABEL KESALAHAN KETIK, DAN TANDA BACA

\begin{tabular}{|c|c|c|c|}
\hline NO & KATA & REVISI & HALAMAN \\
\hline 1 & yangtak & yang tak & 10 \\
\hline 2 & mengan-dung & mengandung & 10 \\
\hline 3 & bertransfor-masi & bertransformasi & 10 \\
\hline 4 & sumberins pirasi & sumber inspirasi & 11 \\
\hline 5 & Pesantren & pesantren & 11 \\
\hline 6 & $a n a k a n a k$ & $a n a k-a n a k$ & 12 \\
\hline 7 & maafyang & maaf yang & 12 \\
\hline 8 & Seluruh & Seluruh & 14 \\
\hline 9 & Acehdan & Aceh dan & 19 \\
\hline 10 & anak-anakAflatoun & anak-anak Aflatoun & 19 \\
\hline 11 & $g e n k$ & geng & 21 \\
\hline 12 & akibat-nya & akibatnya & 22 \\
\hline 13 & ambilkan air, & ambilkan air! & 23 \\
\hline 14 & berkata, begini; & berkata begini, & 42 \\
\hline 15 & $\operatorname{tanyakku}$ & tanyaku & 46 \\
\hline 16 & aBang & abang & 51 \\
\hline 17 & hampi & hampir & 54 \\
\hline 18 & bahasa arab & bahasa Arab & $\infty 0$ \\
\hline 19 & pengin tah & pengin tahu & 65 \\
\hline 20 & launnya & lainnya & 65 \\
\hline 21 & mengutaran & pengutaran & 89 \\
\hline 22 & mempertemuan & mempertemukan & 94 \\
\hline 23 & menjengguk & menjenguk & 96 \\
\hline 24 & hidAyahnya & hidayahnya & 97 \\
\hline 25 & pAyah & payah & 101 \\
\hline 26 & feelingku & feelingku & 101 \\
\hline 27 & bandariaku & bandari aku & 126 \\
\hline 28 & pantani & pak tani & 135 \\
\hline 29 & terauma & trauma & 133 \\
\hline 30 & tarauma & trauma & 132 \\
\hline 31 & batrei & baterai & 139 \\
\hline 32 & berastage & Berastagi & 140 \\
\hline 33 & brestagi & berastagi & 140 \\
\hline 34 & pomusí & promosi & 143 \\
\hline 35 & pejalanku & perjalananku & 143 \\
\hline 36 & PAyahnya & payahnya & 143 \\
\hline 37 & paret & parit & 146 \\
\hline 38 & tangah & tengah & 153 \\
\hline 39 & memoti-vasiku & memotivasiku & 162 \\
\hline 40 & nompr urut & nomor urut & 165 \\
\hline 41 & pelihan & pilihan & 167 \\
\hline 42 & sebenar-nya & sebenarnya & 167 \\
\hline
\end{tabular}

Selain kesalahan ketik, terdapat pula kesalahan logika bahasa yang dapat merusak tatanan suasana pembaca yang sebelumnya sudah dibangun rapi oleh pengarang. Dalam struktur teks karya sastra, bahasa merupakan unsur yang paling utama yang menjadi pondasi dari setiap narasi, latar, watak, plot, dan semua unsur-unsur lain dalam karya sastra. Oleh karena itu, pengarang seharusnya lebih jeli dalam menuangkan gagasannya ke dalam bentuk lambang bahasa yang sesuai dengan kaidah kebahasaan tentunya.
Bahasa Indonesia sebagai bahasa resmi kenegaraan setidaknya mampu menadi jembatan yang mempertemukan antara dunia kreativitas pengarang dan dunia imajinasi pembaca. Wijoto (2009) menegaskan bahwa "Bahasa Indonesia oleh semangatnya yang nasionalis dan kebersamaan, diarahkan pada sifat Uuniversalitas. Bahasa tidak mencerminkan kelas sosial, kalaulah ada, itu hanya pada beberapa kata sapaan. Bahasa yang dipersiapkan untuk "persamaan nasib sosial" bagi masyarakat 


\section{Kadarisman}

penggunanya." Hal tersebut menggambarkan bahwa betapa bahasa Indonesia memiliki sifat universalitas yang seharusnya bisa diterima semua masyarakat dari setiap golongan.

Oleh karena itu, setiap pengarang dalam usaha penyampaian ide dan gagasannya kepada pembaca yang dituangkan ke dalam lambang bahasa, sebaiknya benarbenar memperhatikan kaidah kebahasaan. Meskipun di satu sisi karya sastra merupakan karya fiksi, karya yang tidak harus terikat pada aturan dan sistem ketatabahsaan, tetapi di sisi lain karya sastra terutama yang berbentuk prosa tetap tidak bisa lepas dari kenyamanan pembaca dalam menginterpretasikan karya tersebut. Hal itu dimaksudkan agar tidak terjadi kesalahan interpretasi, kerusakan rasa, dan kehambaran citraan terhadap karya itu sendiri.

Sementara itu, terdapat beberapa kesalahan berbahsa pada novel Ciuman Terakhir Ayah karya Maufiqurrahman Surahman. Selain kesalahan ketik, kesalahan berbahasa pada novel tersebut berupa kekurangsempurnaan logika teks yang dibangun, sehingga menyebabkan perubahan makna. Ada juaga yang berupa ketidakefektifan kalimat yang mengakibatkan ambiguitas makna.

TABEL KESALAHAN BERBAHASA

\begin{tabular}{|c|c|c|c|}
\hline No & KALIMAT & REVSI & HALAMAN \\
\hline 1 & $\begin{array}{l}\text { Saya ucapcan banyak-oanyak farima } \\
\text { kash }\end{array}$ & Saya ucapcan talma kash & 19 \\
\hline 2 & $\begin{array}{l}\text { Tapast manoawakan untick [ a, an } \\
\text { kesukaanku sebagal ongkos } \\
\text { menjaga sarah.... }\end{array}$ & $\begin{array}{l}\text { Tapast manbawacan jajan } \\
\text { kesukaaniou sebagal ongkos } \\
\text { menjaga sarah... }\end{array}$ & 20 \\
\hline 3 & $\begin{array}{l}\text { Aku menunduk sambi mengeamun } \\
\text { sesuatu yang entah apa, aku tak } \\
\text { tahu }\end{array}$ & $\begin{array}{l}\text { Aku manunduk sambi magmun } \\
\text { sesuatu yang entah apa, aku tak } \\
\text { tahu }\end{array}$ & 22 \\
\hline 4 & $\begin{array}{l}\text { Menurut guru agamaku d sako an, } \\
\text { pernah berkata, begint; "Bagl orang } \\
\text { yang tak mampu... }\end{array}$ & $\begin{array}{l}\text { Menurut guru agamaku d seko an, } \\
\text { "bagl orang yang tak mampu... }\end{array}$ & 23 \\
\hline 5 & $\begin{array}{l}\text { Namun sesampa nya kami d atas, } \\
\text { goncangan berkekuatan reatef keras } \\
\text { itu membuat konds!l bangunan. }\end{array}$ & $\begin{array}{l}\text { Namun sesampa nya kam d atas, } \\
\text { goncangan keras litu membuat. } \\
\text { kondlal bangunan.... }\end{array}$ & 31 \\
\hline 6 & $\begin{array}{l}\text { "Nina, tanganmu kenapa? tanya } \\
\text { Paman. } \\
\text { "Tangan Nina Terluka berat, Bang. } \\
\text { Kata doider harus damputasl," } \\
\text { sautiou. }\end{array}$ & $\begin{array}{l}\text { "Nina, tanganmu kenapa?" tanya } \\
\text { paman. } \\
\text { "Tangan Nina Terluka berat, paman. } \\
\text { Kata dokiter harus damputasl," } \\
\text { sautcu. }\end{array}$ & 44 \\
\hline 7 & 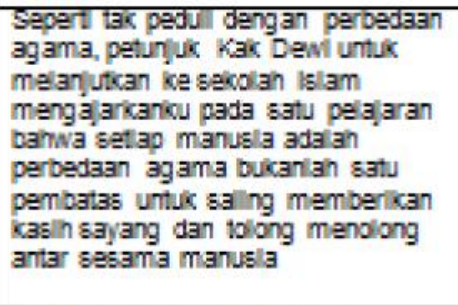 & 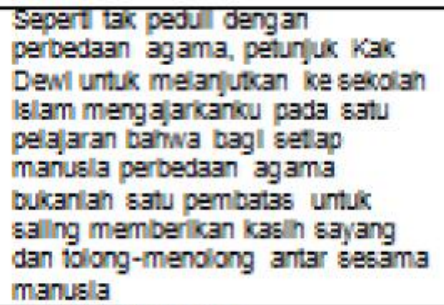 & 53 \\
\hline 8 & $\begin{array}{l}\text { Nama-nama gedung-gedung } \\
\text { pesantren }\end{array}$ & $\begin{array}{l}\text { nama-nama gedung } \\
\text { pesantreninama gedung-gedung } \\
\text { pesantren }\end{array}$ & 60 \\
\hline 9 & $\begin{array}{l}\text { Rak Dew adalah saorang Kristan } \\
\text { yang lalaml }\end{array}$ & & 97 \\
\hline 10 & $\begin{array}{l}\text { Kami yang kedetuan singgan dan } \\
\text { menlikmat salah satu warung litu, }\end{array}$ & $\begin{array}{l}\text { Kam yang kebatuan ginggan dan } \\
\text { man konat makanan ol salah satu } \\
\text { warung ltu, }\end{array}$ & 138 \\
\hline 11 & $\begin{array}{l}\text { Ummi mual mangurang l kecepatan } \\
\text { dan membuka pintu mobll, kemudan } \\
\text { memintaku untuk mematican musk' } \\
\text { darl ponseku }\end{array}$ & $\begin{array}{l}\text { Umim manat kan mobl, kemudan } \\
\text { memintaku untuk mematikan musk } \\
\text { darl ponseku }\end{array}$ & 151 \\
\hline 12 & 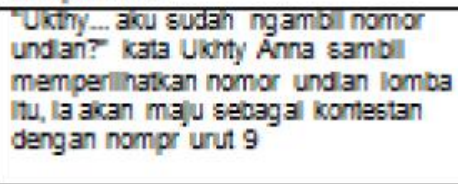 & 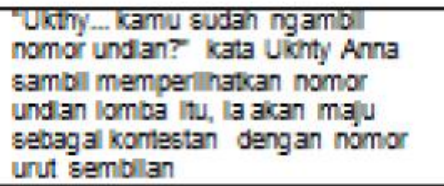 & 165 \\
\hline
\end{tabular}


Sekilas, kesalahan berbahasa tampak sebagai sesuatu yang wajar dan tidak berdampak signifikan terhadap karya seseorang. Akan tetapi jika dikaji lebih lanjut, kesalahan-kesalahan berbahasa itu menciptakan keganjilan lain dalam pikiran pembaca. Semacam ada sesuatu yang mengganjal, yang membuat pembaca kurang nyaman dalam mencerna teks sastra yang dibaca.

Misalnya kutipan pada tabel kesalahan nomor satu, "Saya ucapkan banyak-banyak terima kasih" kata "banyak" pada kutipan tersebut merupakan kata ulang "banyakbanyak." Padahal kata "banyak" sudah menunjukkan jamak, atau kata yang memiliki makna "besar jumlahnya; tidak sedikit". Jadi, pada kalimat tersebut dapat ditafsirkan bahwa tokoh "saya" mengucapkan terima kasih sebanyakbanyaknya, meskipun kata "banyak" sendiri merupakan bentuk lain dari relativitas, karena tidak disertai ukuran pastinya. Seharusnya kalimat tersebut bisa dijadikan sebagai kalimat yang lebih efektif menjadi "saya ucapkan terima kasih."

Sementara, salah satu contoh kesalahan logika teks yang terdapat pada novel Ciuman Terakhir Ayah sebagaimana tercantum pada tabel kesalahan bahasa nomor sepuluh. Pada kalimat "Kami yang kebetulan singgah dan menikmati salah satu warung itu" memiliki makna bahwa "kami" dalam novel Ciuman Terakhir Ayah merupakan orang-orang yang singgah sambil menikmati warung. Tidak dijelaskan oleh pengarang apakah "kami" singgah dan menikmati suasana di warung yang disinggahi, atau menikmati makanan yang dijual di warung yang disinggahi.

\section{Kesimpulan}

Demikianlah beberapa hal yang bisa didapat dari novel Ciuman Terakhir Ayah karya Maufiqurrahman Surahman. Tentu saja setiap karya memiliki kelebihan dan kekurangannya masing-masing. Tapi tidaklah adil jika kita hanya membebankannya kepada penulis, sebab kerja kepenulisan juga tidak akan berhasil tanpa adanya kerjasama yang baik antara penulis, penyunting dan penerbit. Dalam posisi ini, kritikus sastra berada di antara kekurangan dan kelebihan itu, yang menguraikannya secara seimbang. Sejalan dengan pendapat Darmanto (Yudiono, 2009) bahwa "kritik sastra sangat dibutuhkan dalam perkembangan sastra, sedangkan kritik yang ideal adalah kritik yang sesuai dengan fungsi budaya kritik itu sendiri, yaitu untuk menjembatani penikmat dengan karya sastra."

\section{PUSTAKA}

Adnan, Sobih. 2012. Melacak Definisi Nilai Religiusitas dalam Sastra Pesantren. http:// www.nu.or.id/post/read/39522/melacak-definisi-nilai-religiusitas-dalam-sastrapesantren. diakses Tanggal 25 Agustus 2015

Aschroft, Bill dkk. Dalam Soewandi, Fati dan Agus Mokamat. 2003. Menelanjangi Kuasa Bahasa (Teori dan Praktik Sastra Poskolonial). Penerbit Qalam: Yogyakarta.

Faizi, M. Silsilah intelektualisme dan sastra di pesantren (Sebuah Perambahan Atas Tradisi Pesantren, Sastra, Dan Sastra Pesantren). http://www.raedubasha.web.id /2015/05/ seri-sastra-pesantren-3-silsilah.html. diakses Tanggal 25 Agustus 2015 
Kadarisman

Nurrohmat, Binhad. 2009. Gincu Merah Sastra Pesantren. http://sastra-indonesia.com/ 2009/03/gincu-merah-sastra-pesantren/. diakses Tanggal 25 Agustus 2015

Ratna, Nyoman Kutha, S.U. 2009. Teori, Metode, dan Teknik Penelitian Sastra. Pustaka Pelajar: Yogyakarta.

Surahman, Maufiqurrahman. 2013. Ciuman Terakhir Ayah. Group CV. Writing Revolution. Yogyakarta

Wijoto, Ribut. 2009. Kondisi Postmodern Kesusastraan Indonesia. Dewan Kesenian Jawa Timur: Surabaya.

Yudiono. 2009. Pengkajian Kritik Sastra Indonesia. Grasindo: Jakarta. 